Research Article

\title{
Risk Identification and Responses of Tunnel Construction Management during the COVID-19 Pandemic
}

\author{
Zhimin Wang $\mathbb{D}^{1}{ }^{1}$ Zixiao Liu, ${ }^{1}$ and Junyan Liu ${ }^{2}{ }^{2}$ \\ ${ }^{1}$ School of Accounting, Guangdong University of Foreign Studies, Guangzhou 510006, China \\ ${ }^{2}$ School of Economics and Management, Qingdao University of Science and Technology, Qingdao 266061, China \\ Correspondence should be addressed to Junyan Liu; 1_junyan@163.com
}

Received 12 November 2020; Revised 29 November 2020; Accepted 3 December 2020; Published 17 December 2020

Academic Editor: Mingfeng Lei

Copyright (C) 2020 Zhimin Wang et al. This is an open access article distributed under the Creative Commons Attribution License, which permits unrestricted use, distribution, and reproduction in any medium, provided the original work is properly cited.

The COVID-19 pandemic has brought about significant influences to the world, including tunnel construction. Based on the analysis of 12 tunnel construction projects, this paper identifies the specific risk factors related to the COVID-19 pandemic, e.g., men, materials, machines, methods, social environment, and political epidemic prevention pressure. Among these risk factors, worker availability, site accessibility, shortage of construction materials, and inadequate epidemic prevention materials caused by the lockdown policy are the most fundamental challenges encountered by the projects. Social panic and epidemic prevention policy requirements are key issues needed to be addressed before the resumption of construction work. The special circumstances caused by the COVID-19 pandemic called for flexible project management and coordination skills to raise suitable and effective response strategies, while local governments make substantial contributions in solving the difficulties. Although these measures have resulted in higher project costs, their effectiveness in catching up with project schedules is worthy of recognition. The findings of this study enrich the risk categories of tunnel construction and the risk response strategies from the perspective of a global pandemic. It implies that future construction schemes including design, budget, supply chain, and project management should consider the possible influence of an epidemic.

\section{Introduction}

The COVID-19 pandemic has brought about significant changes to human life as well as economic activities. Many activities and works, if possible, have been moved online. Traditional construction work, however, is not on the list. Particularly, with the features of closed construction and poor ventilation, tunnel construction work is under greater risk of epidemic spread and infection, compared to other construction projects. As one of the most important engines to stimulate economy development, infrastructure construction projects are in urgent need of resumption. Under the strictest epidemic control policy in China, tunnel construction during the pandemic encounters different risks, in addition to the traditional risks identified. Yet, limited studies have been devoted to this special agenda of what are the risks of COVID-19 and how they impact tunnel construction projects. By analyzing 12 tunnel construction projects in China, this study aims to explore the special risks and impacts brought about by the COVID-19 pandemic in tunnel construction work as well as the strategies adopted by the project management teams in response to the risk and impact. The findings enrich the studies of risk identification and assessment of construction projects and provide possible implications to tunnel construction management during the COVID-19 pandemic.

\section{Literature Review}

Before the COVID-19 pandemic, the risks related to construction projects had been systematically analyzed and different risk structures had been raised by scholars. For instance, Kangari [1] and Panthi et al. [2] divided risk into aspects of construction-related risks, contractual and legal risk, physical aspects, performance and management, general economic conditions, political, and public. Mustafa and Al-Bahar [3] proposed a classification scheme of project risk categories including acts of physical, financial and 
economical, political and environmental, design, and job site-related risks. This framework of risk categories and factors was adopted and extended by Eskander [4]. Samantra et al. [5] argued that construction risk was laid in engineering design, construction management, construction safety-related, natural hazards, social, and economic. ElSayegh et al. [6] raised a similar risk framework including management risk, technical risk, stakeholder risk, materials and technology risk, and regulatory and economic risk. Schieg [7] emphasized the sources and consequences of risk such as quality, personnel, cost, schedule, strategic decisions, and external environment. Some researchers simplified the risk structure. For example, project risk could be divided into country level, market level, and project level according to the level of risk sources [8]. Zavadskas et al. [9] claimed that risks could be summarized into two aspects, namely, external risk and internal risk. Hamzaoui et al. [10] further divided the internal risks into project stakeholders' risk and project management risk.

Based on the risk structures, researchers have explored specific risks from different perspectives in construction projects. For instance, some scholars focused on the safety issues of construction. They argued that project safety was related to technical risk, geological risk, environmental risk, and other types of risks [11]. Safety interventions by contractors/managers, construction structure and facilities, workers' safety behaviors and attitudes, working surfaces, and platforms were key factors that influenced construction accidents [12]. Risks might also be integrated into the supply chain. Late specification changes, shortage of materials and equipment, late deliveries, bad weather, and suppliers' bad performance would contribute to the project risks of schedule and cost overrun [13-15]. As one of the most important risk factors, human-related issues such as ability, knowledge, skills, experiences, and attitudes of workers, as well as features of the project team, were also emphasized in the risk analysis literature $[16,17]$. On the company level, Zhao et al. [18] raised the importance of the commitment of the board and senior management, risk appetite and tolerance, risk-aware culture, and sufficient resources in influencing construction projects' risks. External environment including political, economical, social, technological, cultural, and legal environment also had a great impact on projects' construction [19-21]. In detail, Khodeir and Mohamed [22] identified a group of political and economic risks such as currency fluctuations, changes in taxation, changes in energy costs, lack of funds, official changes, and workers' strikes. Bosher et al. [23] focused on the impact of disaster risk on construction projects, including natural hazards, human-induced hazards, and climate change. Yuan et al. [24] claimed that project stakeholders of owners, contractors, suppliers, construction supervisor, designers, local residents, government authorities, social communities, and media were key elements of social risk. Some researchers explored construction project risk based on the phases of construction work. For example, Tepeli et al. [25] analyzed the risk of the design phase and found that the top risks included noncompliance to design standards, failure in geotechnical studies, financial resource problems, and changes in law or regulations. Risks of the construction phase involved labor availability and quality, differing site conditions, site access, defective design, property damage, coordination with utilities and adjoining neighbors, and availability of materials $[1,4]$.

The risks identified above would inevitably influence the cost, schedule, and quality of a project [25]. Zhou et al. [26] further extended risk loss into casualty, economic loss, time loss, and social influence. Eshtehardian and Khodaverdi [27] and Luu et al. [28] argued that factors related to owner, design, and construction, as well as external environment, were linked to project schedule delay. Scientists had outlined response strategies towards these risks to eliminate the possible impact of the risks. For instance, from the corporate perspective, recommendations of establishing an organization to be responsible for early warning of risks [22], fostering a sound safety culture, and improving risk awareness training for staff and stakeholders [23, 29] were raised. From a stakeholder perspective, contractors were urged to provide materials on time while owners should be responsible for timely funding payments to prevent time overrun [28]. Coordination among different stakeholders was also important in managing potential risks [30]. Main contractors, utilities, regulatory authorities, financial and country factors, geological conditions, construction processes, and resources were all important factors in controlling project cost and schedule [31, 32].

In summary, the academic has achieved a consensus that risks exist throughout the life cycle of construction projects, including design, implementation, operation, management, and maintenance [33]. However, researchers have developed different thoughts and opinions on risk structures in the construction industry. Yet, among different risk structures, factors such as men, machines, materials, methods, and internal and external environment were common and major causes of risk $[26,34]$. Construction risks could lead to remarkable influences on projects' cost, schedule, and quality $[3,35]$. Although some studies considered the impact of natural disasters such as earthquakes, bad weather, or floods on construction projects, only few of them were conducted under the background of a global pandemic.

\section{Research Framework and Methodology}

3.1. Research Framework. COVID-19 has caused notable influences on all aspects of daily life and economic activities, including the operation of the construction industry. Among which, tunnel construction projects were subjected to more severe challenges from the epidemic for their features of enclosed construction, poor ventilation conditions, and/or remote location. This study focuses on the construction phase of tunnel projects owing to the fact that it requires the most intensive input of on-site labor, materials, and equipment. These factors are directly hit by the COVID-19 epidemic and the correspondent lockdown policy.

The risk framework raised by Zhou et al. [26] is adopted in this study to explore the specific risks brought about by the COVID-19 epidemic. In this framework, the risk factors include men, machines, materials, methods, and 
environment. These factors are directly hit by the pandemic and generate specific risks that are much different from the traditional ones. In addition, issues related to risk factors such as site conditions, labor skills and availability, materials delivery, and equipment malfunction would result in project cost and schedule overruns [36]. Therefore, this study emphasizes two aspects of risk loss caused by the epidemic, namely, schedule delay and cost overrun. However, it should be noted that there might be interactions between these two risk consequences since the measures of catching up with schedule require additional investment, which might lead to an increase in project cost. Based on the analysis, the framework of risk identification and risk loss of this study is shown in Figure 1.

3.2. Methodology. A case study approach is adopted in this paper to explore the risk of COVID-19 and its possible influences on tunnel construction. The projects selected in this study are based on the following criteria: (1) the case must be a typical tunnel construction project; (2) the case should be in the construction process during the COVID-19 epidemic; and (3) the case should report the detailed impacts of the COVID-19 pandemic. Based on these criteria, we searched the construction industry news online with the keywords of "tunnel construction" and "COVID-19" and found that there were 12 typical tunnel construction projects that met the requirements, the information of which is listed in Table 1 . As could be seen, the project types covered water induction tunnel, cross-river tunnel, highway tunnel, highspeed railway tunnel, soundproof tunnel, and subway tunnel construction. The projects were located in different regions of mainland China, including Zhejiang, Guangdong, Hunan, Guizhou, Chongqing, and Beijing, indicating a widespread impact of COVID-19 on the construction industry. An overseas project in Nepal is also included in the case study, aiming to explore the different risks that the project encountered out of China.

\section{Risk Identification and Response Strategies}

4.1. Man Risks. Man risks were the most frequent and fundamental risks which were reported in the projects. Almost all cases in this study claimed that their resumption of construction work was hindered by the difficulties of workers returning due to the lockdown policy. The time of the COVID-19 outbreak in China was around late January 2020, which was overlapped with the Chinese most important traditional holiday, the spring festival. Most of the Chinese people were on holiday back at their hometown for family gatherings at that time. The sudden hit of the COVID19 epidemic activated the highest level of emergency preparedness in most regions of China. Apart from the strictest lockdown policies in Hubei Province, transportation inter provinces and cities in China was also massively canceled to prevent the spread of the disease. The spring festival holiday was then prolonged, and people had to stay at home and wait for the gradual resumption of economic activities. The project manager of Case 2 stated that "most of our shield

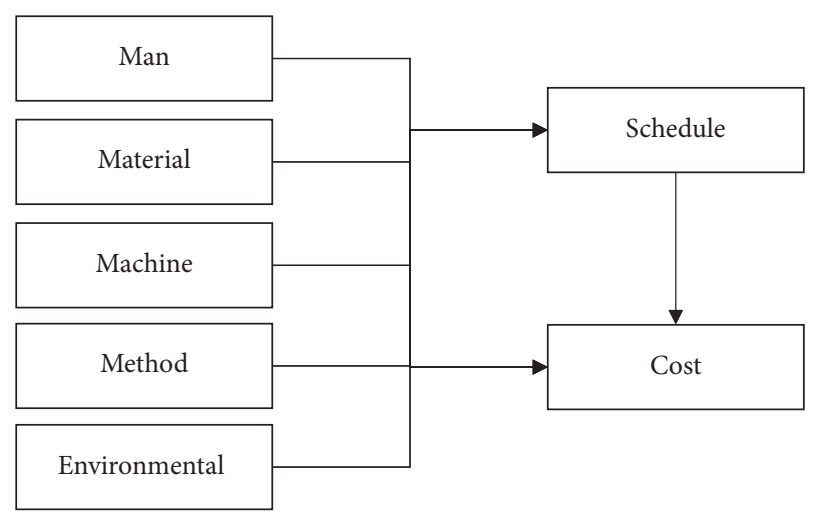

FIgURE 1: Framework of risk identification and risk loss for COVID-19 towards tunnel construction.

construction crew were from northeast China; they were blocked by the lockdown policy and cancellation of flights and trains." The impact of COVID-19 on Case 7 was even more serious. The project manager recalled that "more than $30 \%$ of our workers were from Hubei Province; they were unable to travel back to work due to stricter quarantine policies and longer lockdown period; our project schedule was delayed for about 3 months by then." As shown in Figure 2 that the construction work of Case 7 had to be suspended during the lockdown. The outbreak of COVID-19 in other countries also caused fundamental influences on the construction work. The manager of Case 1 reported that "more than 200 workers were dismissed as requested by the nationwide lockdown policy in Nepal; vehicles and flights were canceled while factories and markets were all closed; we were lacking of workers, equipment operators, and technicians." Thus, the specific man risks in tunnel construction projects during the COVID-19 pandemic was closely related to the interruption of workers' availability and crew accessibility caused by blocked transportation due to local epidemic prevention policies.

Project teams have tried their full efforts to overcome the problems of worker availability and accessibility. The most common measure adopted was to hire chartered buses to directly take the workers back to the construction sites from their hometown (e.g., Cases 3, 4, 6, 8, 9, and 11), as shown in Figure 3. For workers of longer distances, some projects even chartered a plane to facilitate workers' return journey (e.g., Case 2). In Cases 4 and 11, transportation allowances were paid to workers to stimulate their early return to work. Private cars were also important ways for staff's getting back to the construction site in Cases 2 and 5. These methods have a common feature of reducing the chances of workers' exposure to the risks of disease during their journey. Thus, when the workers successfully returned to the construction site and completed their quarantine procedures, the problems of staff shortage could be addressed in the quickest manner.

Yet, chartered home-to-site transportation of workers was not always a suitable strategy. In Case 8 , as mentioned above, $30 \%$ of workers were blocked in Hubei Province until late March by the strictest epidemic prevention policy. Under this 
TABle 1: Cases outline.

\begin{tabular}{|c|c|c|}
\hline No. & Sources and location (accessed on Oct 26, 2020) & Project type \\
\hline 1 & $\begin{array}{l}\text { http://www.xinhuanet.com/fortune/2020-09/05/c_1126456274.htm } \\
\text { Nepal }\end{array}$ & Water-induction tunnel \\
\hline 2 & $\begin{array}{c}\text { http://zj.ifeng.com/a/20200307/12145627_0.shtml } \\
\text { Jinhua, Zhejiang Province }\end{array}$ & Cross-river tunnel \\
\hline 3 & $\begin{array}{c}\text { http://www.zgjtb.com/zhitong/2020-10/26/content_251119.htm Wenzhou, Zhejiang } \\
\text { Province }\end{array}$ & Highway tunnel \\
\hline 4 & $\begin{array}{c}\text { http://www.zgjtb.com/zhuanti/2020-03/02/content_237017.htm Huizhou, Guangdong } \\
\text { Province }\end{array}$ & Highway tunnels \\
\hline 5 & $\begin{array}{c}\text { http://www.zgjtb.com/2020-02/28/content_236785.htm } \\
\text { Chongqing }\end{array}$ & High-speed railway tunnel \\
\hline 6 & http://www.zgjtb.com/zhitong/2020-06/22/content_245049.htm & $\begin{array}{l}\text { High-speed railway soundproof } \\
\text { tunnel }\end{array}$ \\
\hline 7 & $\begin{array}{c}\text { Beijing } \\
\text { http://www.zgjtb.com/zhitong/2020-05/29/content_243523.htm Qingyuan, Guangdong } \\
\text { Province }\end{array}$ & Highway tunnel \\
\hline 8 & $\begin{array}{c}\text { http://www.zgjtb.com/2020-04/20/content_241156.htm } \\
\text { Chongqing }\end{array}$ & Highway tunnel \\
\hline 9 & $\begin{array}{c}\text { http://www.zgjtb.com/zhitong/2020-04/28/content_241692.htm } \\
\text { Lianyuan, Hunan Province }\end{array}$ & Highway tunnel \\
\hline 10 & $\begin{array}{c}\text { http://www.zgitb.com/zhuanti/2020-03/19/content_239029.htm } \\
\text { Zunyi, Guizhou Province }\end{array}$ & Highway tunnel \\
\hline 11 & $\begin{array}{c}\text { http://www.zgjtb.com/2020-04/28/content_241627.htm } \\
\text { Changde, Zhangjiajie, Hunan Province }\end{array}$ & Highway tunnel \\
\hline 12 & $\begin{array}{l}\text { http://www.zgjtb.com/2020-04/30/content_241812.htm } \\
\text { Changsha, Hunan Province }\end{array}$ & Subway tunnel \\
\hline
\end{tabular}

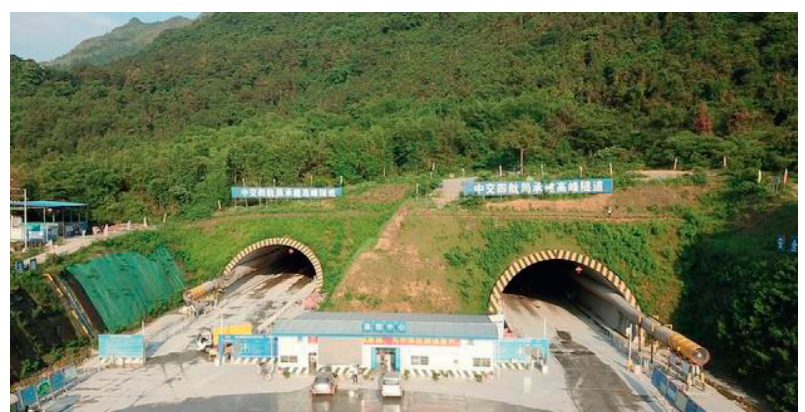

Figure 2: The construction site of Case 7 during the lockdown (source: http://www.zgjtb.com/zhitong/2020-05/29/ content_243523.htm).

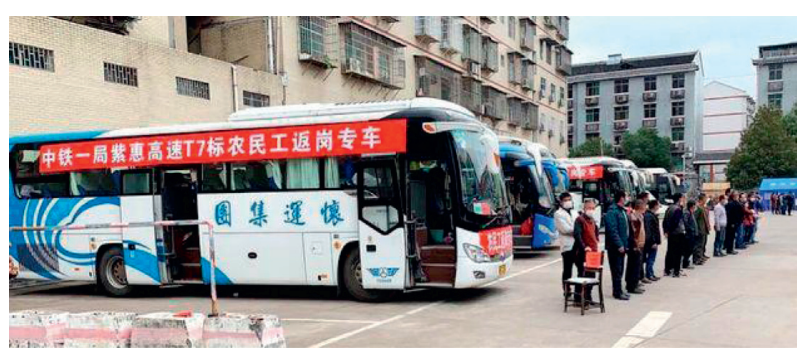

FIgURE 3: Chartered buses for workers returning in Case 4 (source: http://www.zgjtb.com/2020-04/30/content_241812.htm).

situation, the project team decided to hire and train new workers from other provinces and local villages to substitute the blocked Hubei workers. The difficulty in the construction project in Nepal was much harder when alternative workers were also unavailable. "Only about 17 Chinese staff and 9 Nepalese workers were left in the water induction tunnel construction site, and we decided to continue the work with available resources," the manager recalled. The deputy mechanical and electrical manager, who was in charge of operation and maintenance of machinery and equipment, acted as an all-round operator of the excavator, loaders, dump truck operators, and mechanics. Other staff also undertook multiple jobs in the construction site with an aim to catch up with the project schedule.

4.2. Material Risks. Apart from interrupting the on-site workers' availability and accessibility, the COVID-19 prevention policies also disrupted the supply of construction materials. Managers of many projects complained about the shortage of building materials and disease prevention materials. For instance, in Case 4 , managers reported that building material shortage due to insufficient production capability of suppliers was the major problem encountered by the construction project. The project schedule of Case 5 was also hampered by the shortage of supply and delayed delivery of building materials (shown in Figure 4). The material shortage problems for Case 9 were much more severe. The project director recalled that "local shops and markets were closed; the supply of medical materials and living materials were extremely inadequate by that time." The remote location of tunnel construction projects made the supply and delivery of materials more difficult due to the blocked transportation in the countryside at that time.

Communication and coordination skills were vital in solving the problems of materials shortage during the 


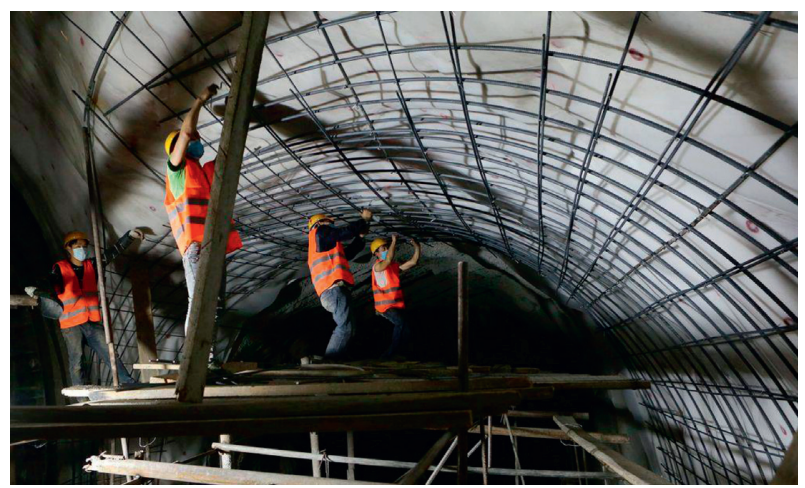

FIGURE 4: Workers were facing the problem of material shortage in Case 5 (source: http://www.zgjtb.com/2020-02/28/content_236785. htm).

pandemic. The project team of Case 4 kept instant communication with suppliers to ensure the supply of cement, steel, and other major construction materials. Considering the fact that the suppliers were also suffering from shortage of workers and materials owing to the lockdown policy, the project team sought assistance from the local governments, who had stronger coordination power and resources at that time. The local government successfully helped to found an exclusive supply of sand and stone for the project from three local factories.

Local governments also made remarkable contributions in solving the problems of subsistence and epidemic prevention material shortage. In Case 9, the local mayor stated that "after acknowledging the difficulties encountered by the construction project, we assigned a designated shop supplier and a procurement officer, who was responsible for the procurement and delivery of goods to the construction site to address their daily life problems." For epidemic prevention material supplies, the mayor also contacted and coordinated with enterprises and successfully ordered thousands of masks and disinfectants to support the resumption of construction work. In Case 11, the local government also donated thousands of masks and disinfectants and other epidemic prevention materials to the construction project to facilitate the work resumption.

4.3. Machine Risks. Similar to material shortages, construction projects were encountered with untimely equipment supply and delivery, due to disruption of production by machine suppliers and transportation. Yet, machine risks were not commonly reported by the projects in this study. Only Case 5 claimed that their construction schedule was hindered due to delayed delivery of equipment. The reasons lied on the features of tunnel construction, of which equipment and machines such as shield machines were set up at the first procedure of the construction work. When the construction work began, changes and replacement of large equipment and machines would be less frequent. However, for the projects in the process of starting, the delay in equipment and machine delivery and setup would greatly hamper the construction process.
4.4. Method Risks. The method risks brought about by the COVID-19 epidemic were different from the traditional tunnel construction methods but related to the epidemic prevention methods and project coordination methods. According to the epidemic prevention policy in China, all working places should meet the basic requirements including epidemic prevention plans, materials, and specific measures before they could apply for work resumption. COVID-19 safety had become the priority issue, and a leader team on epidemic prevention and control was set up in most projects during the epidemic. Construction projects which failed to meet the epidemic prevention standard/criteria would be shut down by the administration departments. The epidemic control in tunnel construction projects was stricter, as they were under greater risk of disease spread owing to poorer ventilation conditions in the enclosed working site. Thus, various measures and response strategies were adopted by the project teams aiming to pursuit an earlier work resumption. For instance, in Cases 4, 9, and 10, professionals were invited to give online or on-site COVID19 safety training to the staff. Prevention and control measures such as disinfection and ventilation in tunnel construction sites, offices, and public areas were conducted in Cases 3 and 5 (shown in Figure 5). Masks and other medical supplies were provided to employees, and their temperatures were monitored in a daily manner (displayed in Figure 6) (e.g., Cases 5, 11, and 12). COVID-19 testing was arranged for the workers, and separate prefabricated houses were built or used for 14 days quarantine before the workers could be back to the tunnel construction site (Cases 2, 4, 9, and 12). High-technology methods were also applied to eliminate the disease risk using big data to verify the travel track of the workers within 30 days (Case 2). Upon resumption of work, most of the project teams were under closed-off management to ensure workers' health and project safety at the early stage. Measures such as appropriate arrangement of working and resting, reducing labor intensity, avoiding excessive fatigue, and psychological and emotional counseling were also implemented to the epidemic management scheme (Case 8).

Under the circumstances and difficulties of limited workers, materials, and equipment during the COVID-19 pandemic, specific project management and coordination skills were required. Apart from the measures of promoting workers' returning and material supply discussed above, the on-site construction management scheme was equally or even more vital. While waiting for the recovery of the supply chain, project management teams took the inventory of major construction materials and formulated corresponding construction measures based on the resources on-site. Project teams optimized the allocation of workers, equipment, and funds and ensured the key and control segments which significantly affected the construction schedule were firstly resumed (e.g., Cases 4, 5, and 10). New working hours were established, and the schedule was adjusted. Provided that the requirements for epidemic prevention were met, some projects arranged a 24-hour continuous operation plan (Cases 2 and 5). Additional funds were arranged for schedule node award, while construction contests (depicted in 


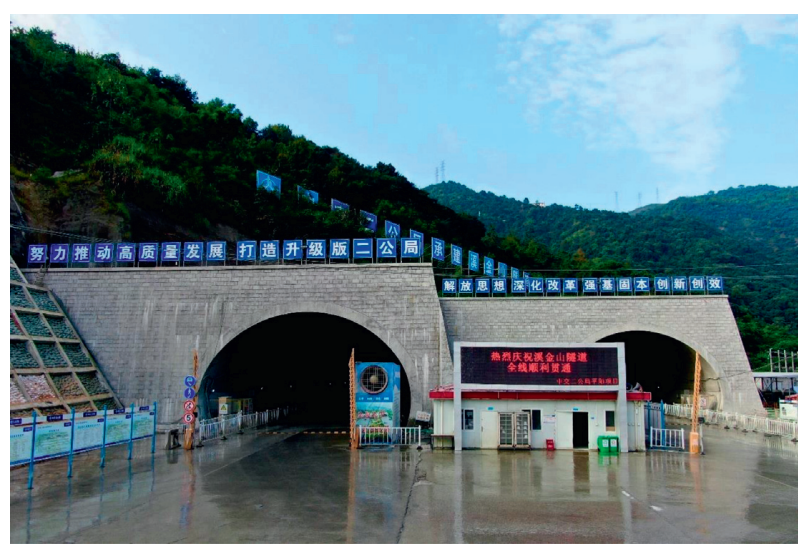

Figure 5: Ventilation and disinfection in Case 3 (source: http:// www.zgjtb.com/zhitong/2020-10/26/content_251119.htm).

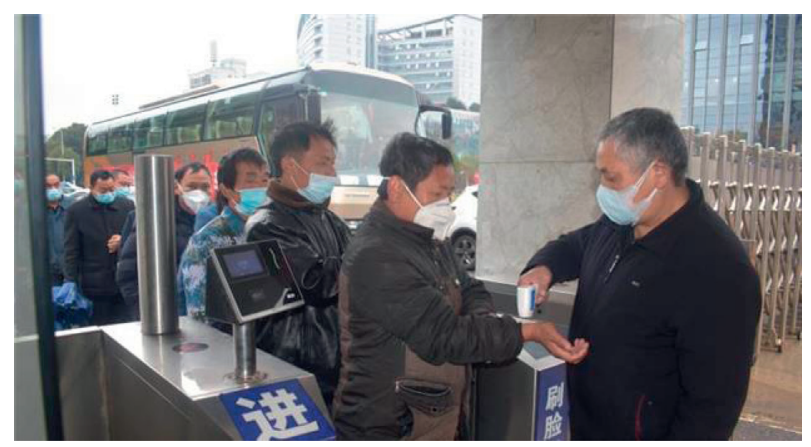

FIGURE 6: Checking the body temperatures of workers before they enter into the construction site in Case 12 (source: http://www. zgjtb.com/2020-04/30/content_241812.htm).

Figure 7) were held to stimulate the workers' enthusiasm to catch up with the schedule delay (e.g., Cases 7, 8, and 11).

4.5. Environmental Risks. In addition to the traditional environmental risks such as political, economical, social, technological, cultural, and legal, the specific environmental risks encountered by tunnel construction during COVID-19 were related to social pressure and political epidemic prevention pressure. For social pressure, Cases 4 and 9 were typical examples in this study. In Case 4, when the tunnel construction work was planned to resume in mid-February, the residents around the construction site were panicked about the workers' migrating back. By that time, the whole society was under intensive fear of epidemic spread, especially in the countryside regions where the tunnel construction projects were located. Village residents were more conservative about the epidemic spread that they even spontaneously blocked their roads, and non-native residents were not allowed in. As reported in Case 9, "the roads to the construction site were blocked by towns and villages nearby due to the strictest preventive measures in mid-February. Workers were unable to return to the tunnel construction site while materials could not be delivered in." To eliminate the panic among villagers and solve the problems of site accessibility, the project turned to the local government for

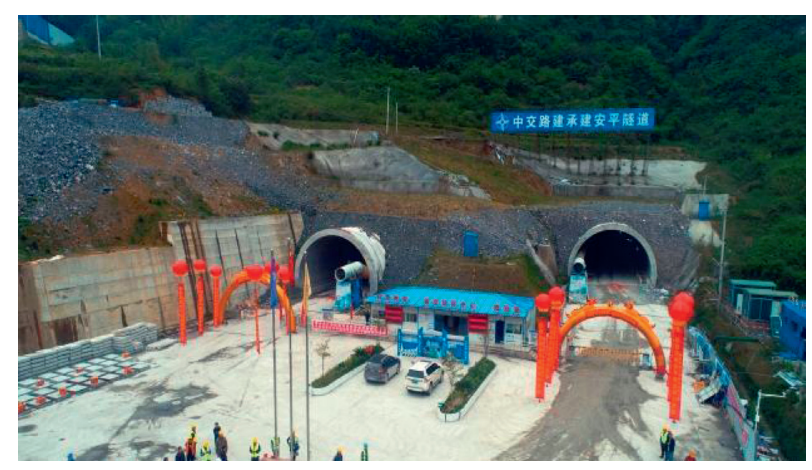

Figure 7: Working contest was held in Case 11 (source: http:// www.zgjtb.com/zhitong/2020-04/28/content_241692.htm).

assistance. Together with local government officers, project leaders visited those villages to win understanding and support from the residents by explaining epidemic knowledge and national policy to them. At the same time, more than 60 temporary quarantine observation points were established by integrating staff dormitories and building container board rooms to meet the requirements of epidemic prevention as well as reduce panic among local residents. Apart from the above measures, the project team also coordinated with resource allocation and firstly resumed construction sections that were relatively further away from residential areas. Some construction sites even made special causeways for construction workers to commute.

The political risks faced by the project teams during COVID-19 were related to the strictest epidemic prevention policies in China. In mid-February, the resumption of work must meet the epidemiological standards before the administration permission was granted. Every construction site must establish epidemic prevention plans and measures, with project managers serving as leaders of the epidemic prevention teams. Regular sterilization was required after the work was resumed. The epidemic control measures for tunnel construction projects were stricter due to their poorer ventilation in enclosed working conditions. Local government and epidemic prevention departments were responsible for the overall organization and regular inspection of epidemic prevention measures conducted in the working site.

4.6. Summary of COVID-19-Related Risk and Response Strategies. In summary, the risks brought about by the COVID-19 pandemic towards tunnel construction projects include man risk, material risk, machine risk, method risk, and environmental risk. Major issues of man risk included interruption of staff's accessibility to the construction sites and shortage of workers, technicians, and operators. Project teams adopted measures such as chartered buses and planes, private cars, or travel allowances to promote the early return of workers from their hometowns. For situations when workers were unable to return due to strict lockdown policies, new workers were hired and trained or available staff undertaking multiple jobs with suitable measures to 
meet the urgent demand of human resources. Construction materials and machines were in short supply as the supply chain also encountered inadequate staff and materials due to the lockdown policy. The blocked transportation in towns and villages made the delivery of materials more difficult for tunnel construction projects. Apart from keeping communication with suppliers, local governments have made great contributions in solving the problems of material shortage. Construction projects had to meet the epidemiological standards (e.g., medical materials, plans, and measures) as well as address the panic of near-site residents before their work could be resumed. Under the circumstance of inadequate resources and tight schedule pressure, coordinate skills and management schemes such as optimal resource allocation and working contests were vital in catching up with the tunnel construction progress. The risk issues and response strategies identified in Sections 4.1-4.5 are listed in Table 2.

\section{Discussion}

5.1. The Specialties of Tunnel Construction Risks Related to COVID-19. The analysis in this study identified the specific risks brought by the outbreak of the COVID-19 pandemic. Major risks are related to the difficulties encountered by the tunnel construction projects in terms of site accessibility, worker availability, shortage of construction materials, and blocked transportation. However, these difficulties are not referred to the structure of the labor market (e.g., labor skills and capacity), site conditions such as roads and location, and supply chain disruption, which have been identified in previous studies, e.g., Panthi et al. [2], Abd El-Karim et al. [36], and Abas et al. [14]. The underlying reasons of these staff and material shortage problems are the overlapping of Chinese traditional spring festival with the epidemic outbreak and the disruptions of worker's migration journey back to work due to the lockdown policy. Apart from tunnel construction projects, the supply chain was also affected by the countrywide shutdown. These difficulties could be solved by bridging the accessibility gap between workers and their workplaces when the epidemic is under control in most regions in China. Measures such as chartered buses and planes, private cars, or travel allowances are suitable to promote the early return of workers from their hometowns. New workers could also be hired and trained or available staff could undertake multiple jobs to meet the urgent demand of human resources.

The scope of coordination in project management, supply chain management, and public relationship management is wider during the COVID-19 pandemic. Under a strict epidemic prevention policy in China, the resumption of economic and production activities was followed in a gradual manner, including the supply of construction materials and equipment. Project management teams had to coordinate with suppliers and transportation departments to seek for an early recovery of material supply. They also had to adjust resource allocation plans to optimize their usage and mitigate the impact of material shortage. Additional campaigns and contests were held to stimulate the project progress. Epidemic prevention trainings, epidemic prevention materials, quarantine facilities, and psychological counseling were arranged for the staff. Lastly, project management teams needed to devote extra efforts in public relationship management, as the residents around the tunnel construction sites were panicked about the migration of workers. These additional management schemes are vital in solving the difficulties in the tunnel construction projects brought about by COVID- 19 .

Under a specific situation of countrywide shutdown during the pandemic, local governments became a stronger force in tunnel project management. On the one hand, local governments provided substantial assistance in solving the difficulties encountered by the projects to facilitate their work resumptions. For instance, they coordinated the supply and delivery of construction materials, living materials, and epidemic prevention materials for the projects. They also helped to ease the social panic of the residents around construction sites. Yet, the epidemic prevention guidelines set by the Chinese government in all working places required additional resources and management efforts, as discussed above. It is worth to be noted that the government forces and its contributions to tunnel construction projects in other countries and regions might be different from the cases in this study, due to the diversity of epidemic prevention policies.

\subsection{The Impacts of COVID-19 on Tunnel Construction} Projects. The fundamental and direct impact of COVID-19 on tunnel construction was schedule delay. Similar to traditional risk impacts identified in studies such as Pehlivan and Öztemir [37], Hossen et al. [32], and Eshtehardian and Khodaverdi [27], shortage of workers, materials, machines, and site accessibility had greatly hindered the schedule of the tunnel construction projects at the early outbreak of the COVID-19 epidemic in China. To catch up with the schedule delay, different strategies were implemented to address the risk issues identified. Yet most of the strategies would inevitably lead to an increase in project costs. For instance, to overcome the problems of worker shortage, measures adopted by the project included hiring chartered cars or planes to pick up workers back to the construction sites, providing traffic allowances to workers to promote them to return earlier. For other man risks, strategies such as hiring and training new workers or undertaking multiple jobs also required additional costs. When there was a shortage of construction materials and machines, the negotiation and coordination with suppliers either by project teams or through government departments for urgent resources would lower their bargain power and might have to pay higher prices. In addition, the delivery of materials and equipment under the circumstance of countrywide lockdown would be time and cost consuming, especially for the remote tunnel construction site. Last but not least, construction management schemes were the most important way to catch up with construction progress, in which additional funds had to be invested. Increase in salaries for overtime work was an important way to promote the 
TABLE 2: Summary of COVID-19 risks in tunnel construction projects.

\begin{tabular}{|c|c|c|}
\hline Risk category & Risk identification & Response strategies \\
\hline Men & $\begin{array}{l}\text { Interruption of staff's accessibility to site and shortage of workers, } \\
\text { technicians, and operators }\end{array}$ & $\begin{array}{l}\text { Chartered buses and planes } \\
\text { Private cars or travel allowance } \\
\text { Hire and train new workers } \\
\text { Undertake multiple jobs }\end{array}$ \\
\hline Materials & $\begin{array}{c}\text { Interruption of material supply } \\
\text { Materials delivery difficulties } \\
\text { Shortage of epidemic prevention materials }\end{array}$ & $\begin{array}{l}\text { Communicate with suppliers } \\
\text { Sought assistance from local governments } \\
\text { Coordinate with transportation department }\end{array}$ \\
\hline Machine & Machine supply and delivery & $\begin{array}{l}\text { Coordinate with suppliers and transportation } \\
\text { departments }\end{array}$ \\
\hline Method & Construction management methods & $\begin{array}{c}\text { Training of epidemic prevention } \\
\text { COVID-19 testing and quarantine } \\
\text { High-technology monitor } \\
\text { Epidemic prevention materials and measures } \\
\text { Optimal allocation of resource available } \\
\text { Schedule adjustment } \\
\text { Construction contest and award }\end{array}$ \\
\hline Environmental & $\begin{array}{l}\text { Panic of local residents } \\
\text { Administrative epidemic control policy }\end{array}$ & $\begin{array}{c}\text { Communication with local residents } \\
\text { Sought assistance from local government } \\
\text { Build up quarantine places } \\
\text { Resume working site further away from villages } \\
\text { Establish epidemic prevention leader group } \\
\text { and measures }\end{array}$ \\
\hline
\end{tabular}

progress of construction work. Construction contests and labor campaigns were effective motivations of front-line workers, but additional funds for bonuses were required. All these measures were proved to be effective since many cases reported that they were catching up with the schedule progress although it was achieved at the expense of higher project costs.

The stricter epidemic prevention measures conducted by tunnel construction projects according to the government policies also required extra investment. Under the epidemic prevention policy, additional medical materials as well as regular sterilization work were needed. Supplementary training of epidemic prevention methods had to be held for the staff. Free COVID-19 testing was arranged to workers, and quarantine procedures and places were established. Each prevention measure would need additional expenditures, thus leading to an increase in project costs.

\section{Conclusions}

The COVID-19 pandemic has brought about significant influences on the world, including the construction industry. With the features of enclosed working and poor ventilation conditions, tunnel construction was under greater risk of epidemic spread and infection, compared to other construction projects. By analyzing 12 tunnel construction projects, this paper identified the specific risks related to the COVID-19 pandemic. Factors of men, materials, machines, methods, social panic, and political epidemic prevention pressure were key elements of the COVID-19 risk structure. Among these risk factors, worker availability, site accessibility, shortage of construction materials, and inadequate epidemic prevention materials were the most fundamental challenges encountered by the projects. Social panic and epidemic prevention requirements were key issues needed to be addressed before the resumption of construction work. These risks encountered by tunnel construction projects under the COVID-19 pandemic were of great difference compared to the traditional ones, which called for a more flexible and wider scope of project management and coordination skills to raise suitable and effective response strategies. Project management teams have to devote full effort to facilitating workers' return journey, communicating with suppliers, and stimulating project progress. During the pandemic, local governments in China made substantial contributions in solving the difficulties for they had better coordination capabilities under a countrywide shutdown.

The most essential impacts of COVID-19-related risks on tunnel construction projects were schedule delays and cost overruns. The difficulties of site accessibility, worker availability, material shortage, and panic of surrounding residents had significantly hindered construction progress. Project teams had raised various measures to promote the construction schedule, but their success was achieved at the expense of higher project costs. The epidemic prevention measures conducted by the construction projects also caused extra costs, such as medical supplies, COVID-19 testing, quarantine, and workplace sterilization.

This study contributes to the body of knowledge by enriching the risk categories of tunnel construction as well as response strategies from the perspective of a global pandemic. The specific risks brought by COVID-19 to tunnel construction projects are related to the difficulties of site accessibility and worker availability, shortage of construction materials, and blocked transportation due to the shutdown policy. Measures of bridging the accessibility gap 
between workers and their workplaces are suitable strategies to address the difficulties. Under the specific pandemic circumstances, the scope of coordination in project management, supply chain management, and public relationship management became wider and local government is acting as a stronger force in tunnel project management. Yet, the major limitation of this study is that the conclusions are generated based on the qualitative analysis of secondary information of 12 tunnel construction projects during the COVID-19 epidemic. Field investigations, interviews, and questionnaire surveys could be conducted in the future to validate our findings. In addition, the risk analysis of this study is focused on the construction phase, since we assume that this phase is under direct and severe attack by the pandemic. Future tunnel construction schemes including design, budget, supply chain, and project management should consider the possible influence of a global pandemic, and the impacts of the pandemic on other phases of tunnel construction should be further explored.

\section{Data Availability}

Some or all data, models, or code generated or used during the study are available from the corresponding author upon request.

\section{Conflicts of Interest}

The authors declare that there are no conflicts of interest regarding the publication of this paper.

\section{Acknowledgments}

This work was supported by the National Office for Philosophy and Social Science of China (Youth Project) (no. 17CSH028).

\section{References}

[1] R. Kangari, "Construction risk management," Civil Engineering Systems, vol. 5, no. 3, pp. 114-120, 1988.

[2] K. Panthi, S. M. Ahmed, and S. O. Ogunlana, "Contingency estimation for construction projects through risk analysis," International Journal of Construction Education and Research, vol. 5, no. 2, pp. 79-94, 2009.

[3] M. A. Mustafa and J. F. Al-Bahar, "Project risk assessment using the analytic hierarchy process," IEEE Transactions on Engineering Management, vol. 38, no. 1, pp. 46-52, 1991.

[4] R. F. A. Eskander, "Risk assessment influencing factors for Arabian construction projects using analytic hierarchy process," Alexandria Engineering Journal, vol. 57, no. 4, pp. 4207-4218, 2018.

[5] C. Samantra, S. Datta, and S. S. Mahapatra, "Fuzzy based risk assessment module for metropolitan construction project: an empirical study," Engineering Applications of Artificial Intelligence, vol. 65, pp. 449-464, 2017.

[6] S. M. El-Sayegh, S. Manjikian, A. Ibrahim, A. Abouelyousr, and R. Jabbour, "Risk identification and assessment in sustainable construction projects in the UAE," International Journal of Construction Management, pp. 1-10, 2018.
[7] M. Schieg, "Risk management in construction project management," Journal of Business Economics and Management, vol. 7, no. 2, pp. 77-83, 2006.

[8] S. Q. Wang, M. F. Dulaimi, and M. Y. Aguria, "Risk management framework for construction projects in developing countries," Construction Management and Economics, vol. 22, no. 3, pp. 237-252, 2004.

[9] E. K. Zavadskas, Z. Turskis, and J. Tamošaitiene, "Risk assessment of construction projects," Journal of Civil Engineering and Management, vol. 16, no. 1, pp. 33-46, 2010.

[10] F. Hamzaoui, F. Taillandier, R. Mehdizadeh, D. Breysse, and A. Allal, "Evolutive risk breakdown structure for managing construction project risks: application to a railway project in Algeria," European Journal of Environmental and Civil Engineering, vol. 19, no. 2, pp. 238-262, 2015.

[11] A. La Grange and F. Pretorius, "Ontology, policy and the market: trends to home-ownership in Hong Kong," Urban Studies, vol. 37, no. 9, pp. 1561-1582, 2000.

[12] K. Hu, H. Rahmandad, T. Smith-Jackson, and W. Winchester, "Factors influencing the risk of falls in the construction industry: a review of the evidence," Construction Management and Economics, vol. 29, no. 4, pp. 397-416, 2011.

[13] J. Gosling, M. Naim, and D. Towill, "Identifying and categorizing the sources of uncertainty in construction supply chains," Journal of Construction Engineering and Management, vol. 139, no. 1, pp. 102-110, 2013.

[14] M. Abas, S. B. Khattak, T. Habib, and U. Nadir, "Assessment of critical risk and success factors in construction supply chain: a case of Pakistan," International Journal of Construction Management, pp. 1-9, 2020.

[15] A. Badea, G. Prostean, G. Goncalves, and H. Allaoui, "Assessing risk factors in collaborative supply chain with the analytic hierarchy process (AHP)," Procedia - Social and Behavioral Sciences, vol. 124, pp. 114-123, 2014.

[16] V. Thevendran and M. J. Mawdesley, "Perception of human risk factors in construction projects: an exploratory study," International Journal of Project Management, vol. 22, no. 2, pp. 131-137, 2004.

[17] E. Cheraghi, M. Khalilzadeh, S. Shojaei, and S. Zohrehvandi, "A mathematical model to select the risk response strategies of the construction projects: case study of saba tower," Procedia Computer Science, vol. 121, pp. 609-616, 2017.

[18] X. Zhao, B.-G. Hwang, and S. P. Low, "Critical success factors for enterprise risk management in Chinese construction companies," Construction Management and Economics, vol. 31, no. 12, pp. 1199-1214, 2013.

[19] R. H. Ansah and S. Sorooshian, "Effect of lean tools to control external environment risks of construction projects," Sustainable Cities and Society, vol. 32, pp. 348-356, 2017.

[20] T. Yuan, P. Xiang, H. Li, and L. Zhang, "Identification of the main risks for international rail construction projects based on the effects of cost-estimating risks," Journal of Cleaner Production, vol. 274, Article ID 122904, 2020.

[21] L. Y. Shen, G. W. C. Wu, and C. S. K. Ng, "Risk assessment for construction joint ventures in China," Journal of Construction Engineering and Management, vol. 127, no. 1, pp. 76-81, 2001.

[22] L. M. Khodeir and A. H. M. Mohamed, "Identifying the latest risk probabilities affecting construction projects in Egypt according to political and economic variables. From January 2011 to January 2013," HBRC Journal, vol. 11, no. 1, pp. 129-135, 2015.

[23] L. Bosher, A. Dainty, P. Carrillo, J. Glass, and A. Price, "Integrating disaster risk management into construction: a 
UK perspective," Building Research \& Information, vol. 35, no. 2, pp. 163-177, 2007.

[24] J. Yuan, K. Chen, W. Li, C. Ji, Z. Wang, and M. J. Skibniewski, "Social network analysis for social risks of construction projects in high-density urban areas in China," Journal of Cleaner Production, vol. 198, pp. 940-961, 2018.

[25] E. Tepeli, F. Taillandier, and D. Breysse, "Multidimensional modelling of complex and strategic construction projects for a more effective risk management," International Journal of Construction Management, pp. 1-22, 2019.

[26] H. Zhou, Y. Zhao, Q. Shen, L. Yang, and H. Cai, "Risk assessment and management via multi-source information fusion for undersea tunnel construction," Automation in Construction, vol. 111, Article ID 103050, 2020.

[27] E. Eshtehardian and S. Khodaverdi, "A Multiply Connected Belief Network approach for schedule risk analysis of metropolitan construction projects," Civil Engineering and Environmental Systems, vol. 33, no. 3, pp. 227-246, 2016.

[28] V. T. Luu, S.-Y. Kim, N. V. Tuan, and S. O. Ogunlana, "Quantifying schedule risk in construction projects using Bayesian belief networks," International Journal of Project Management, vol. 27, no. 1, pp. 39-50, 2009.

[29] F. Wang, L. Ding, P. E. D. Love, and D. J. Edwards, “Modeling tunnel construction risk dynamics: addressing the production versus protection problem," Safety Science, vol. 87, pp. 101115, 2016.

[30] P. X. W. Zou, G. Zhang, and J. Wang, "Understanding the key risks in construction projects in China," International Journal of Project Management, vol. 25, no. 6, pp. 601-614, 2007.

[31] V. Maruvanchery, S. Zhe, and T. L. K. Robert, "Early construction cost and time risk assessment and evaluation of large-scale underground cavern construction projects in Singapore," Underground Space, vol. 5, no. 1, pp. 53-70, 2020.

[32] M. M. Hossen, S. Kang, and J. Kim, "Construction schedule delay risk assessment by using combined AHP-RII methodology for an international NPP project," Nuclear Engineering and Technology, vol. 47, no. 3, pp. 362-379, 2015.

[33] M. Rasool, T. Franck, B. Denys, and Niandou Halidou, "Methodology and tools for risk evaluation in construction projects using Risk Breakdown Structure," European Journal of Environmental and Civil Engineering, vol. 16, no. 1, pp. s78-s98, 2012.

[34] I. Y. Wuni, G. Q. Shen, R. Osei-Kyei, and S. AgyemanYeboah, "Modelling the critical risk factors for modular integrated construction projects," International Journal of Construction Management, pp. 1-14, 2020.

[35] A. Taroun and J.-B. Yang, "A DST-based approach for construction project risk analysis," Journal of the Operational Research Society, vol. 64, no. 8, pp. 1221-1230, 2013.

[36] M. S. B. A. Abd El-Karim, O. A. Mosa El Nawawy, and A. M. Abdel-Alim, "Identification and assessment of risk factors affecting construction projects," HBRC Journal, vol. 13, no. 2, pp. 202-216, 2017.

[37] S. Pehlivan and A. E. Öztemir, "Integrated risk of progressbased costs and schedule delays in construction projects," Engineering Management Journal, vol. 30, no. 2, pp. 108-116, 2018. 